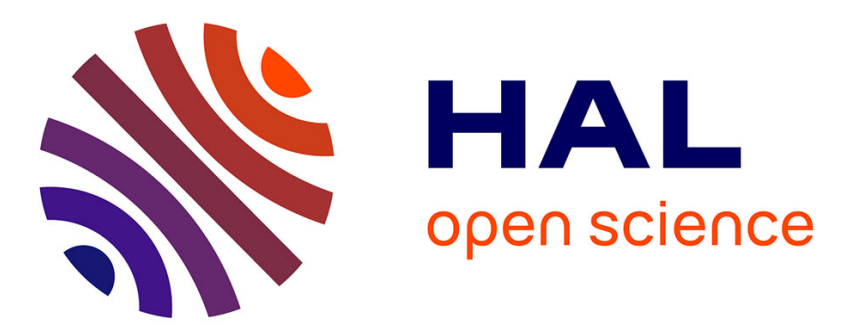

\title{
Optimization of pre-polishing parameters on a 5-axis milling machine
}

Mourad Moumen, Julien Chaves-Jacob, Mohamed Bouaziz, Jean-Marc Linares

\section{To cite this version:}

Mourad Moumen, Julien Chaves-Jacob, Mohamed Bouaziz, Jean-Marc Linares. Optimization of prepolishing parameters on a 5-axis milling machine. International Journal of Advanced Manufacturing Technology, 2016, 85 (1-4), pp.443-454. 10.1007/s00170-015-7944-y . hal-01454770

\section{HAL Id: hal-01454770 \\ https://hal.science/hal-01454770}

Submitted on 2 May 2018

HAL is a multi-disciplinary open access archive for the deposit and dissemination of scientific research documents, whether they are published or not. The documents may come from teaching and research institutions in France or abroad, or from public or private research centers.
L'archive ouverte pluridisciplinaire HAL, est destinée au dépôt et à la diffusion de documents scientifiques de niveau recherche, publiés ou non, émanant des établissements d'enseignement et de recherche français ou étrangers, des laboratoires publics ou privés. 


\title{
Optimization of pre-polishing parameters on a 5-axis milling machine
}

\author{
Mourad MOUMEN ${ }^{\text {a }}$, Julien CHAVES-JACOB ${ }^{\mathrm{b} *}$, Mohamed BOUAZIZ ${ }^{\mathrm{a}}$, Jean-Marc \\ LINARES ${ }^{b}$
}

${ }^{a}$ Ecole Nationale Polytechnique, Département de Génie Mécanique, Laboratoire de recherche Génie Mécanique et Développement.10 avenue Hassan Badi, BP 182, El Harrach (Alger) 16200, Algérie

${ }^{b}$ Aix-Marseille Université, CNRS, ISM UMR 7287, 13288, Marseille cedex 09, France

${ }^{*}$ Corresponding author

julien.CHAVES-JACOB@univ-amu.fr

Telephone number: +33(0) 442939096

Fax number: +33 (0) 442939070

\section{Abstract:}

Pre-polishing and polishing stages are considered as semi-finishing and finishing stages in workpiece production. As a rule, these operations are carried out manually. These stages are health hazards for the operator and may lead to geometrical defects on workpieces. This paper proposes and optimizes a method to perform these operations on a common 5-axis milling machine. This method uses the flank of a flexible cylindrical tool to link the machine position and the exerted polishing pressure. The toolpath proposed comprises a carrier trajectory on which a loop pattern is repeated. Subsequently, experimental optimization of the pre-polishing cost is proposed, coupled with an estimation of the roughness obtained. Firstly, a screening Design Of Experiments is used to identify the most influential factors of this process. Based on these influential factors, a response surface is used to obtain experimental models to estimate the pre-polishing cost per volume and resulting roughness. These models are used to optimize the pre-polishing factors to reduce the process cost whilst maintaining specific roughness.

\section{Keywords:}

Toolpath; 5-axis milling; Polishing; Biomedical; Optimization

\section{Introduction}

Today, pre-polishing and polishing operations are carried out manually. For example, Hilerio et al. [1] present the Product Life Management (PLM) of knee prostheses. Fig. 1 shows the production process of a femoral part of a knee prosthesis and highlights manual pre-polishing and polishing operations. These operations are health hazards for the operator. A study presented by Lison et al. [2] emphasizes the pathogenesis of lung disease produced by airborne cobalt particles (standard alloy used for these prostheses). Furthermore, the geometrical result of the polishing steps, performed manually, depends on the operator's skills and experience. 


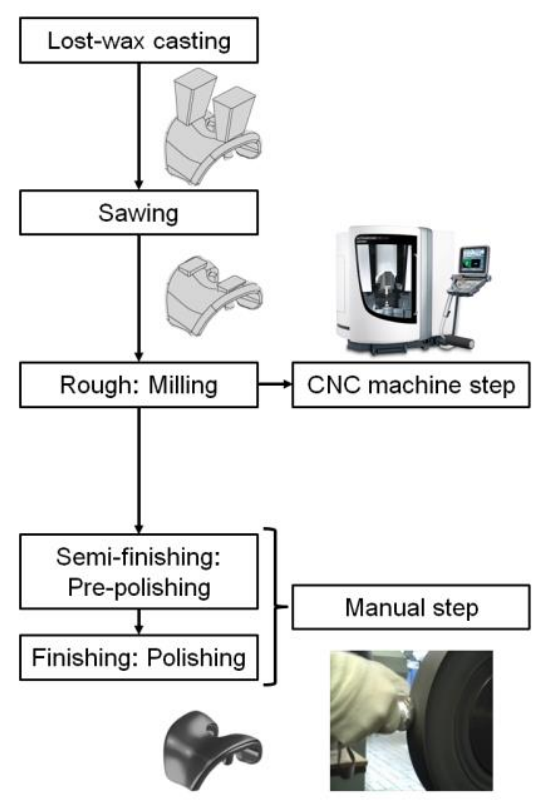

Fig. 1 Production of knee prostheses

Pre-polishing operations are intended for reducing surface roughness (generated through milling, casting ...) and for reducing the polishing-step time. To carry out this stage, a machine able to do complex kinematics and access all sides of the free-form surfaces must be used. Another fundamental issue, when carrying out pre-polishing operations with a CNC machine, is to control the contact force between the polishing tool and the workpiece. In fact, an operator can adapt the pre-polishing toolpath to exert a constant force between the tool and workpiece while a machine is commonly controlled only in position.

In recent years, the scientific community has tried to specify a process to automate freeform surface polishing. To do this, authors have proposed to develop specific machines. Tsai and Huang [3] designed a specific 5-axis machine to carry out polishing operations. A force control loop was developed on this machine. The polishing operation was carried out with a flexible foam-laminate tool on which sandpaper was mounted. Roswell et al. [4] proposed a specific machine using the pneumatic control of polishing forces through pressure control; this machine is also used in Liao et al's research [5]. The proposed machine comprised two linear crossed axes on which a robot tripod was mounted. This solution used a rigid grinding tool. To estimate the induced polishing pressure, authors used a hertz model. Moreover, 5 and 6-axis industrial robots may be used to carry out pre-polishing and polishing operations. This type of machine is interesting due to its low cost but in return its geometrical accuracy is reduced (about $0.1 \mathrm{~mm}$ ). Ryuh et al. [6] have used a 6-axis robot on which a pneumatic system was adapted to control the applied polishing force. Nagata et al. [7] added a combined control of the tool position and force on a 6-axis robot to polish free-form molds. Lin and lu [8] proposed to carry out free-form surface polishing with a 6-axis robot. They adapted and smoothed a milling toolpath generated by a standard CAM system.

Frequently, pre-polishing and polishing stages are carried out after a milling operation. Thus, authors used the milling machine directly to conduct such finishing stages. The method has the advantage of preventing the loss of the workpiece reference frame. Wu et al. [9] suggested that a 3-axis milling machine be used to polish free-form surfaces with flexible ball-end milling. Polishing with a 3-axis machine requires the use of a ball-end tool to solve this problem authors recommended the use of a 5-axis milling machine. Pessoles and Tournier [10] used a 5-axis milling machine on which a flexible disk, with sandpaper attached to the end, was mounted. An experimental study was carried out to estimate and control the polishing force generated by flexible tool deformation. Feng et al. [11] used a similar process and proposed a theoretical study to predict the force exerted. Chaves-Jacob 
et al. [12] used the flank of a flexible cylinder tool to carry out polishing operations on a 5axis milling machine.

To optimize the pre-polishing and polishing stages, the removal material flow rate needs to be estimated. It is difficult to estimate the removal material flow rate which depends on a wide range of parameters. Thus, Tsai et Huang [3] used an empirical approach with Design Of Experiments (DOE) to optimize polishing parameters. Wang et al. [13], using a numerical model, demonstrated that the removal material flow rate is mainly influenced by polishing contact pressure. At the same time, roughness and undulation must be controlled. The flexibility or inflexibility of the tool will greatly influence the polishing roughness obtained. Numerous authors studied rigid tools, similar to grinding operations. Ahn et al. [14] propose an experimental approach based on an acoustic recording of the polishing process to estimate roughness obtained. Using this information Ahn et al. (2002) optimized polishing pressure, feed rate and tool wear. Denkena et al. [15] theoretically estimated the roughness with a rigid corner-radius end-tool used in 5-axis. This model was made based on the nominal tool envelope. This model estimates the surface obtained and it was used to derive roughness indicators. Savio et al. [16] suggested another approach based on the AbbottFirestone curve. Hertz theory was used to determine the tool engagement to clip the AbbottFirestone curve at a defined height. The last two models consider only the tool envelope. Xi and Zhou [17] proposed a method to estimate surface roughness considering grinding grits. This method started out by modeling the polishing tool. In this study, the value of grit diameter is randomly selected. Thereafter, the tool obtained was used to perform virtual geometrical machining of the workpiece material. Furthermore, roughness estimations, using a flexible tool are, commonly, carried out experimentally as presented by Huissoon et al. [18].

This paper proposes and optimizes a process to carry out the pre-polishing stage on a 5axis CNC milling machine. The first section will present the pre-polishing method and associated parameters. These parameters are classified into two categories: process parameters and toolpath parameters. The second section will propose a screening design of experiment to indentify the main factors influencing pre-polishing cost. The last section will develop proposed pre-polishing process optimization. This optimization was undertaken to reduce the production cost whilst maintaining acceptable roughness.

\section{Pre-polishing process on a 5 axis CNC machine}

The proposed method uses the cylindrical flank side of a polishing tool. Presented developments are carried out with pre-polishing on free-form surfaces. To perform this operation a 5-axis CNC machine is used. The use of the tool flank to pre-polish a free-form surface imposes the tool axis variation along the toolpath, hence the use of a 5-axis machine. The method is illustrated in Fig. 2. The toolpath used comprises carrier trajectories which cover the whole polished surface. The elementary patterns are added on these carrier toolpaths to obtain a looping movement. Fig. 3 presents an example of a polished pattern on an industrial workpiece. One of the aims of this paper is to optimize this elementary pattern shape. On the other hand, the use of a CNC machine tool induces the problem of controlling the pressure contact between the tool and the polished surface. A CNC machine controls the tool position in relation to the polished surface. However, one of the main parameters in a polishing operation is the tool contact pressure on the surface. Thereby, a flexible tool is used to carry out the polishing operations on a CNC machine. The elasticity of the tool is used to link polishing pressure to the CNC machine tool position. The proposed method is defined by parameters linked to the process and the toolpath. 


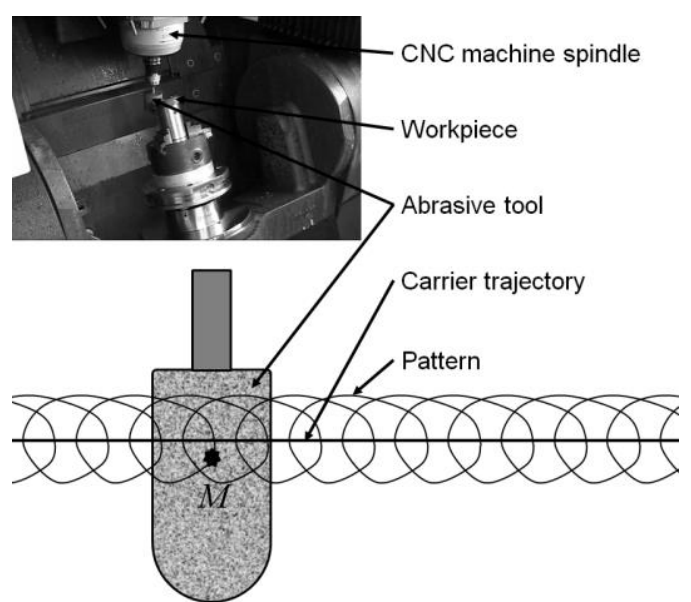

Fig. 2: Illustration of the polishing method

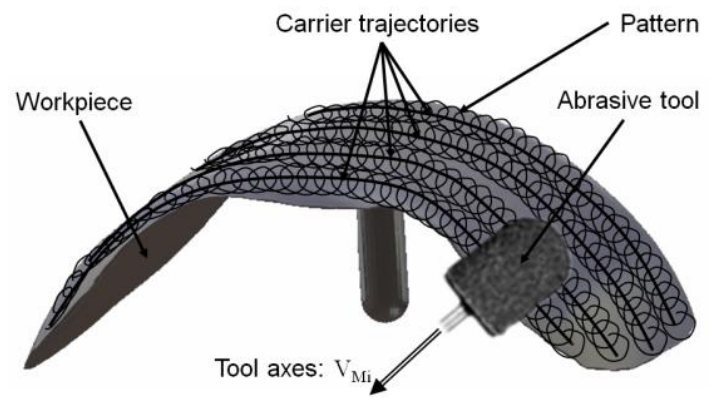

Fig 3: Example of developed polishing toolpath

\section{1) Pre-polishing process parameters}

The pre-polishing process presented is carried out with a flexible tool. This tool is composed of a rubber support on which an abrasive cap in sandpaper is mounted. Different caps are available with different grit sizes. The grit size is defined by a number; when this number increases the grit size decreases. For example, caps with grit numbers of 150 and 320 have respectively an average grit size of $100 \mu \mathrm{m}$ and $46 \mu \mathrm{m}$.

Furthermore, the polishing process has intrinsic characteristics such as kinematic parameters: spindle rotation speed $(R P M)$ and feed rate $(V f)$ respectively specified in rotation/min and $\mathrm{mm} / \mathrm{min}$. During pre-polishing, lubrication may be added to improve the polishing operation. Radial engagement is also one of the process parameters, but this parameter has a specific role in polishing. A nominal radial engagement is specified during the process. This nominal engagement induces tool deformation which creates the tool contact pressure. The removal material rate is directly linked to the contact pressure. If the contact pressure returns to zero the removal material also returns to zero. The toolpath also comprises an important role as regards the pre-polishing process. Section $\$ 2.2$ hereinafter details all the toolpath parameters.

\section{2) Toolpath parameters}

The toolpath plays an important role as regards the pre-polishing process. The toolpath proposed is composed of a carried toolpath use to cover the entire surface and an elementary pattern repeated along this carried toolpath. The morphology of this pattern directly determines the number of times that the tool will pass on an elementary workpiece surface.

The elementary pattern is based on the trochoidal curve. Fig. 4 a) illustrates a trochoidal pattern and its two main parameters. The first parameter, $R$, defines the amplitude of the trochoidal pattern. Parameter a defines the progression by looping. The pattern shape is defined by these two parameters: 
- $a<R$ : the pattern resembles a circle. This type of pattern passes many times over a same point on the surface.

- $a=R$ : the pattern passes exactly three times over each point on the surface.

- $a>R$ : the pattern resembles a sinusoid. This type of pattern passes only once over the surface without any looping movement.

Thus, these two parameters define the shape of the pattern and the number of times which the tool passes over a point on the surface. This number is obtained with Eq. 1.

$$
\text { number of passes }=\text { floor }\left[4^{\star} R / a+1\right]
$$

Subsequently, this pattern is applied in a 3D space along the carrier toolpath to impose the number of patterns per millimeter. Fig. 4 b) illustrates this distortion and presents the parameter $N$ : number of patterns per millimeter.

a) Pattern in $2 D$ pattern space

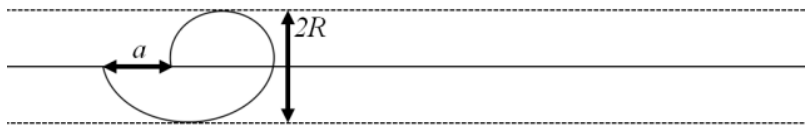

b) Patterns in $3 D$ toolpath space

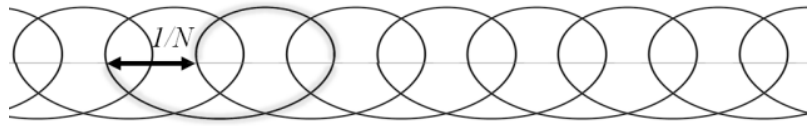

Fig. 4: a) Definition of the elementary pattern used, b) Distorted pattern on the carrier toolpath

Subsequently, two types of patterns are used: trochoidal and triangular. The first one is the real mathematical trochoidal curve. The second is defined to optimize the surface covering and tool wear. Fig. 5 illustrates these two types of patterns.

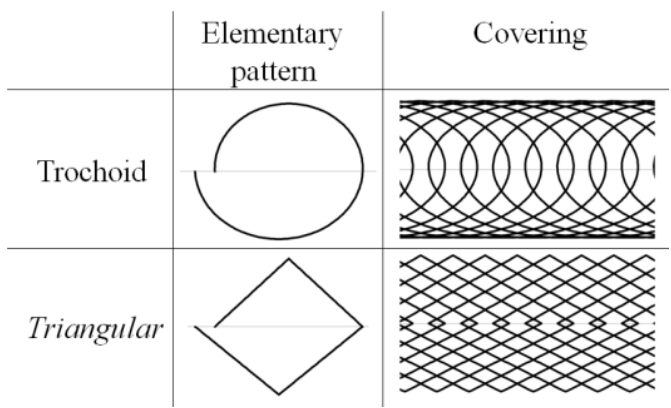

Fig. 5: Two pattern types used

\section{3) Determination of influential factors using a screening design of experiments}

The pre-polishing process proposed has a great number of parameters, see $\S 2$. These parameters do not all have the same influence on pre-polishing process efficiency and quality. In this section a DOE is implemented with a screening method to identify the parameters influencing the pre-polishing process cost per volume the most.

\section{1) Screening parameters}

To carry out the screening test, thresholds and ceilings need to be defined for all factors tested. Table 1 presents these factors with associated parameter names and levels. To carry out this test, a cylindrical tool with a ball-end is used. This tool has a nominal diameter of $13 \mathrm{~mm}$ and a usable cylindrical part of $12 \mathrm{~mm}$. Two types of abrasive caps are used: one with a grit number of 150 and the other with 320 . The second factor represents the use of 
lubricant. The lubricant used is a grinding lubricant with low-fat content and pressure of around 5 bars. $0.05 \mathrm{~mm}$ and $0.1 \mathrm{~mm}$ are respectively the threshold and ceiling of the radial engagement tested. RPM values are 6,000 and $12,000 \mathrm{rpm}$, which respectively induce cutting speeds of 245 and $490 \mathrm{~m} / \mathrm{min}$. The feed rate values, $V f$, are 1,000 and $3,000 \mathrm{~mm} / \mathrm{min}$. The $R$ parameter of the trochoidal pattern is fixed equal to $4 \mathrm{~mm}$. Thereby, $8 \mathrm{~mm}$ of the $12.5 \mathrm{~mm}$ of the cylindrical part of the tool will be used. Fig. 6 illustrates the shape of the pattern used. At the low level $(a=40)$ the pattern resembles a sinusoid and the tool passes only once over the surface. At the high level $(a=1)$ the pattern resembles a circle and the tool passes 17 times over a point on the surface. Two numbers of patterns per millimeter are tested: 0.5 and 4 patterns $/ \mathrm{mm}$. Moreover, the trochoidal pattern is at threshold level and the optimized pattern, triangular, is at ceiling level.

\begin{tabular}{|l|l|l|l|}
\hline Parameter name & Parameter & Threshold $(-1)$ & Ceiling $(+1)$ \\
\hline$X 1$ & Grit number & 150 & 320 \\
\hline$X 2$ & Lubrication & No & Yes \\
\hline$X 3$ & Radial engagement & $0.05 \mathrm{~mm}$ & $0.1 \mathrm{~mm}$ \\
\hline$X 4$ & $R P M$ & $6,000 \mathrm{rpm}$ & $12,000 \mathrm{rpm}$ \\
\hline$X 5$ & $V f$ & $1,000 \mathrm{~mm} / \mathrm{min}$ & $3,000 \mathrm{~mm} / \mathrm{min}$ \\
\hline$X 6$ & $a(R=4 \mathrm{~mm})$ & 40 & 1 \\
\hline$X 7$ & $N$ & 0.5 pattern $/ \mathrm{mm}$ & 4 patterns $/ \mathrm{mm}$ \\
\hline$X 8$ & Pattern shape & Trochoidal & Triangular \\
\hline
\end{tabular}

Table 1: Factors tested for the screening design of experiment

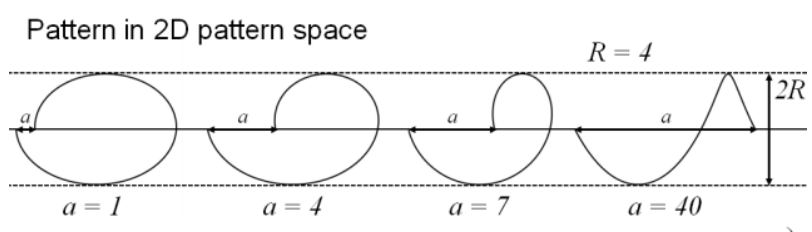

a)

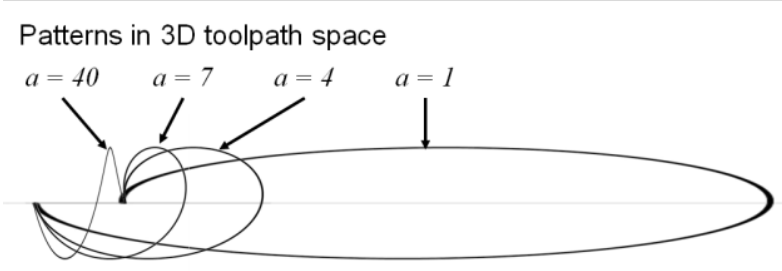

Fig. 6: Pattern shape tested in the DOE

Fig. 7 illustrates the experimental environment. The pre-polished surface is a cylinder with $8 \mathrm{~mm}$ of diameter in $100 \mathrm{cr} 6$ (steel with $1 \%$ of carbon and $1.5 \%$ of chrome; Brinell hardness $195 \mathrm{HB}$ ). Pre-polishing length is $40 \mathrm{~mm}$. Each experiment starts with a fresh surface and it is comprises 3 passes. Each pass is programmed with the nominal radial engagement. This means that the last pass is programmed with 3 times the radial engagement as compared to the fresh surface.

Table 2 presents the experiment carried out for the screening design of experiment. Twelve experiments are planned with a Hadamard matrix with two repetitions of one test. 


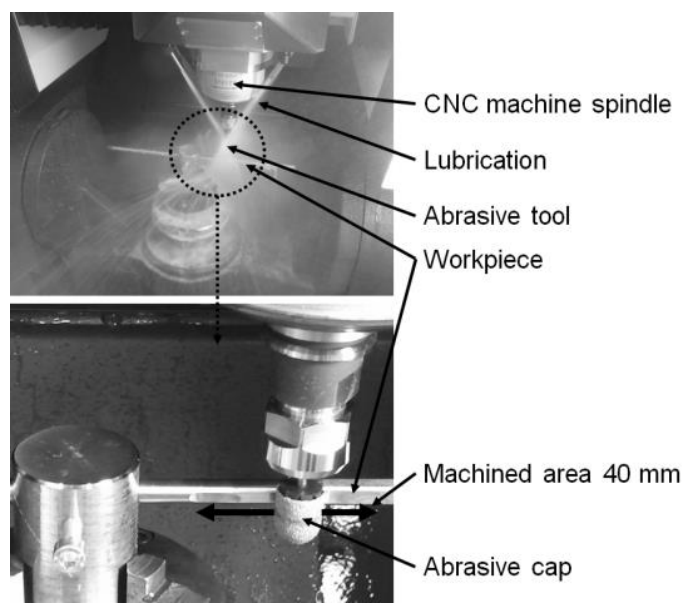

Fig. 7: Pre-polishing tests carried out

\begin{tabular}{|l|l|l|l|l|l|l|l|l|}
\hline $\begin{array}{l}\text { Experiment } \\
\text { number }\end{array}$ & $\begin{array}{l}\text { Grit } \\
\text { number }\end{array}$ & Lubrication & $\begin{array}{l}\text { Radial } \\
\text { engagement } \\
(\mathrm{mm})\end{array}$ & $\begin{array}{l}R P M \\
(\mathrm{rpm})\end{array}$ & $\begin{array}{l}V f \\
(\mathrm{~nm} / \mathrm{min})\end{array}$ & $\begin{array}{l}N \\
(\text { Pattern/mm) }\end{array}$ & Pattern \\
\hline 1 & 320 & Yes & 0.05 & 12,000 & 3,000 & 1 & 0.5 & Trochoidal \\
\hline 2 & 150 & Yes & 0.1 & 6,000 & 3,000 & 1 & 4 & Trochoidal \\
\hline 3 & 320 & No & 0.1 & 12,000 & 1,000 & 1 & 4 & Triangular \\
\hline 4 & 150 & Yes & 0.05 & 12,000 & 3,000 & 40 & 4 & Triangular \\
\hline 5 & 150 & No & 0.1 & 6,000 & 3,000 & 1 & 0.5 & Triangular \\
\hline 6 & 150 & No & 0.05 & 12,000 & 1,000 & 1 & 4 & Trochoidal \\
\hline 7 & 320 & No & 0.05 & 6,000 & 3,000 & 40 & 4 & Triangular \\
\hline 8 & 320 & Yes & 0.05 & 6,000 & 1,000 & 1 & 0.5 & Triangular \\
\hline 9 & 320 & Yes & 0.1 & 6,000 & 1,000 & 40 & 4 & Trochoidal \\
\hline 10 & 150 & Yes & 0.1 & 12,000 & 1,000 & 40 & 0.5 & Triangular \\
\hline 11 & 320 & No & 0.1 & 12,000 & 3,000 & 40 & 0.5 & Trochoidal \\
\hline 12 & 150 & No & 0.05 & 6,000 & 1,000 & 40 & 0.5 & Trochoidal \\
\hline $12 \_1$ & 150 & No & 0.05 & 6,000 & 1,000 & 40 & 0.5 & Trochoidal \\
\hline $12 \_2$ & 150 & No & 0.05 & 6,000 & 1,000 & 40 & 0.5 & Trochoidal \\
\hline
\end{tabular}

Table 2: Experiments carried out with screening design of experiment

\section{2) Screening responses: definition of the objective functions}

The pre-polishing operation is a semi-finishing operation. Its main objective is to suppress the scallops caused by the rough milling operation (scallops between two ball-end tool passes). Consequently, the objective function was to reduce the pre-polishing cost, maintaining a surface quality to avoid overcost during the finishing step. Eq. 2 presents the computation of the pre-polishing cost, PPcost. This cost is composed of three terms:

- First, the cost of machine time to achieve the pre-polishing operation. This cost is computed with the cost per hour of the machine multiplied by the pre-polishing time. It is the addition of the real pre-polishing time, Time computed with eq. 3, and the tool change time. This is equal to the number of tool changes necessary to achieve the pre-polishing operation ( $N$ _change computed with eq. 4) multiplied by the time to change a tool (Time_change).

- Secondly, the cost of the tool (Tool_cost) is deducted using eq. 6.

- Lastly, the constant cost (Cst) includes for example, the cost to make the workpiece fixture, preparation cost, etc.

$$
\begin{aligned}
& P P_{\text {With: }} \text { cost }=\text { Time } \\
& \text { * Cost } / h+N \text { _change }{ }^{*} \text { Time_change }{ }^{*} \text { Cost } / h+\text { Tool_cost }+C s t \\
& \text { Time }
\end{aligned}
$$

Time: duration of pre-polishing operation, only the time where the tool machines the workpiece. 
Cost/h: cost of the 5-axis CNC machine per hour.

$N$ change: number of tool changes necessary during the pre-polishing operation.

Tool_cost: cost of tools to carry out the pre-polishing operation.

Cst: constant costs in pre-polishing operations.

$$
\text { Time }=\mathrm{Vol} / \mathrm{Q}
$$

With:

Vol: volume of removal material.

$Q$ : removal material flow rate.

N_change $=$ Time $/$ Tool_Life_duration

With:

Tool_Life_duration: the tool life duration is computed with the eq. 5 .

Tool_Life_duration $=$ Tool_usable $/$ Wear_speed

With:

Tool_usable: Usable Tool volume.

Wear_speed: wear speed of the usable volume of the tool.

Tool_cost $=$ N_change ${ }^{*}($ Caps + Support/10 $)$

With:

Caps: caps cost.

Support: the support cost; support may be changed about every 10 caps.

Eq. 7 was obtained combining Eq. 2 to 6 . This equation highlights that the cost of a prepolishing operation depends only on removal material flow rate $(Q)$, tool wear speed (Wear_speed) and constant values. Thereafter, the polishing cost will be computed using:

- Removal material flow rate: this parameter is computed dividing the removal material by the machining time. Removal material is computed multiplying the machined length $(40 \mathrm{~mm}$ see Fig. 7) by the average machined surface. This surface is obtained averaging the machined surface at both ends of the machined region. The machined surface, at each end, is computed using the disk portion area equation and measuring the real radial engagement with a micrometer. The machining time is provided by the CNC machine, only the time where the tool machines the workpiece is considered. $Q$ is expressed in $\mathrm{mm}^{3} / \mathrm{s}$

- Tool wear speed: the profile of each tool is measured before and after the pre-polishing operation. This profile is obtained measuring several tool diameters, in the working zone of the tool, with a laser CNC machine option. Finally, the wear area between the tool profile before and after pre-polishing is divided by the machining time to obtain the tool wear speed. Wear_speed is expressed in $\mathrm{mm}^{2} / \mathrm{s}$

$P P \_$cost $=($Vol $/ Q){ }^{*}\left[\right.$ Cost/h + Wear_speed $/$ Tool_surface ${ }^{*}\left\{\right.$ Time_change ${ }^{*}$ Cost $/ h+($ Caps + Support/10 $\left.\left.)\right\}\right]+$ Cst

Furthermore, the machined surface roughness must be controlled. The purpose of the work presented is to optimize the pre-polishing process, but this optimization should not increase polishing stage time much.

\section{3) Screening results and discussions}

In the DOE method, screening experiments are used to determine the influential factors. Furthermore, if no interaction is present, screening may also provide information on the direction of influence of each factor on the response parameters. To analyze the screening results a numerical model (Eq. 8) is associated with the response ( $Y$ which represents firstly cost per volume and secondly surface roughness). The best fit is carried out with a MoorePenrose pseudo inverse method. In the model obtained, if $b i$ is positive that means that when $X i$ changes from low to high level the value of the response increases. Furthermore, the higher the absolute value of $b i$, the more influence the $X i$ factor has on the response. 
Table 3 provides all experimental results. The Cost by pre-polished volume is computed using Eq. 7. The numerical values used to carry out this computation are:

- Cost/h is $€ 125 / h$;

- Caps is €0.5;

- Support is €3.6;

- Time_change is $10 \mathrm{~min}$.

$Y=b 0+b 1 \cdot X 1+b 2 \cdot X 2+b 3 \cdot X 3+b 4 \cdot X 4+b 5 \cdot X 5+b 6 \cdot X 6+b 7 \cdot X 7+b 8 \cdot X 8$

With:

$X i$ : value of the i factor.

$b i$ : coefficient associated with the i factor.

\begin{tabular}{|l|l|l|l|l|}
\hline $\begin{array}{l}\text { Experiment } \\
\text { number }\end{array}$ & $\begin{array}{l}Q \\
\left(\mathrm{~mm}^{3} / \mathrm{s}\right)\end{array}$ & $\begin{array}{l}\text { Wear_speed } \\
\left(\mathrm{mm}^{2} / \mathrm{s}\right)\end{array}$ & $\begin{array}{l}\text { PP_cost/Vol } \\
\left(€ / \mathrm{mm}^{3}\right)\end{array}$ & $\begin{array}{l}\text { Roughness } \\
(\mu \mathrm{m})\end{array}$ \\
\hline 1 & 0.0156 & 0.0190 & 17.35 & 0.838 \\
\hline 2 & 0.0626 & 0.0085 & 2.55 & 1.57 \\
\hline 3 & 0.0190 & 0.0028 & 5.19 & 0.815 \\
\hline 4 & 0.0244 & 0.0052 & 5.12 & 1.03 \\
\hline 5 & 0.1699 & 0.0302 & 2.30 & 1.77 \\
\hline 6 & 0.0152 & 0.0020 & 6.02 & 1.05 \\
\hline 7 & 0.0097 & 0.0051 & 12.64 & 1.09 \\
\hline 8 & 0.0071 & 0.0067 & 19.64 & 0.896 \\
\hline 9 & 0.0199 & 0.0024 & 4.76 & 0.458 \\
\hline 10 & 0.2339 & 0.0185 & 1.14 & 6.71 \\
\hline 11 & 0.1203 & 0.0518 & 5.15 & 6.02 \\
\hline 12 & 0.0159 & 0.0196 & 17.42 & 3.71 \\
\hline $12 \_1$ & 0.0271 & 0.0180 & 9.60 & 3.53 \\
\hline $12 \_2$ & 0.0244 & 0.0188 & 11.07 & 4.89 \\
\hline
\end{tabular}

Table 3: Experimental results

\subsection{1) Pre-polishing cost per volume}

The model presented by Eq. 8 is associated with the determined cost per volume (presented in table 3) to obtain the bi coefficients presented in table 4. Fig. 8 provides a histogram presentation of bi values and a Pareto chart of these values. This curve is obtained plotting the cumulative effects in percent of each factor starting by the most influential. This curve is used to determine the limit between the factors influencing or not. Here below is the classification of factors, starting with the most influential, for reducing production cost per volume:

- $X 3$ (very influential): $b 3$ value is negative, which means that to reduce the pre-polishing cost it is necessary to increase the radial engagement.

- X1 (influential): a low level of the grit number (150) reduces the production cost. Thereby, a high grit size reduces the operation cost.

- $X 7$ (influential): numerous patterns per millimeter are necessary to reduce the prepolishing cost.

- $X 4$ (influential): an augmentation of the spindle rotation decreases the production cost.

- X5 (not very influential): to reduce the pre-polishing cost the feed rate may be increased.

- X8 (not very influential): a triangular pattern reduces the production cost compared to a trochoidal pattern.

- X6 (not very influential): a pattern that resembles a circle increases the pre-polishing cost compared to a pattern that resembles a sinusoid.

- X2 (not influential): lubrication does not significantly influence the pre-polishing cost. 


\begin{tabular}{|c|c|c|}
\hline & PP_cost/Vol: bo & 8.27 \\
\hline Grit number & PP_cost/Vol: b1 & 2.51 \\
\hline Lubrication & PP_cost/Vol: b2 & 0.15 \\
\hline Radial engagement & PP_cost/Vol: b3 & -4.76 \\
\hline RPM & PP_cost/Vol: b4 & -1.61 \\
\hline$V f$ & PP_cost/Vol: $b 5$ & -0.75 \\
\hline$a$ & PP_cost/Vol: b6 & 0.57 \\
\hline$N$ & $P P \_c o s t /$ Vol: $b 7$ & -2.23 \\
\hline Pattern & PP_cost/Vol: b8 & -0.60 \\
\hline
\end{tabular}

Table 4: Numerical model of cost by removed volume
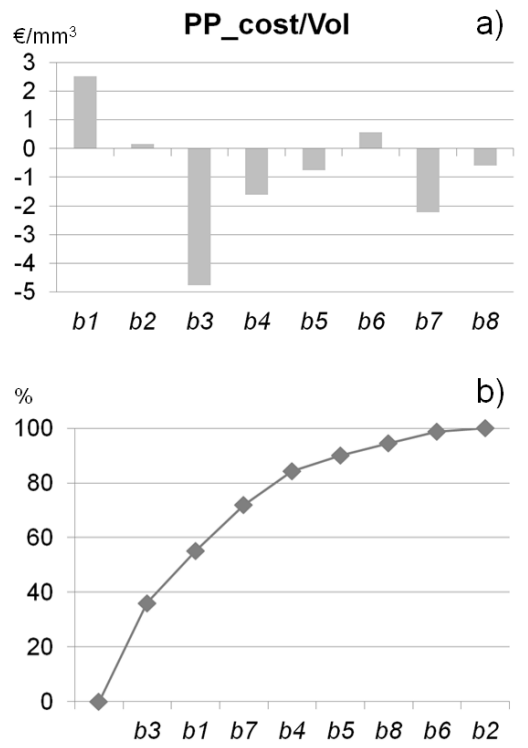

Fig. 8: Model coefficients for pre-polishing cost per volume: a) Histogram and b) Pareto chart

\subsection{2) Surface roughness}

Surface roughness is an important constraint at the end of the pre-polishing process. Surface roughness measures were accurately characterized through optical measurements using the chromatic confocal sensing CMM. The resolution of this CMM is about $40 \mathrm{~nm}$. Measurements were carried out on a line of $30 \mathrm{~mm}$ with $4 \mu \mathrm{m}$ step. Thereafter, the form defect is suppressed and no other filters were added; thereby, the surface undulation is considered in its presented roughness. Next, the arithmetic average is computed without more filtering than the form defect suppression. Table 5 and Fig. 9 present the coefficient values of the associated model (Eq. 8). Here below is the classification of influential factors, starting with the highest, to reduce surface roughness:

- X7 (very influential): increasing the number of patterns per millimeter significantly reduces surface roughness.

- X6 (very influential): parameter, $a$, determines the shape of the pattern and the number of times that the toolpath passes over a same point on the surface (see $\$ 3.1$ ). With a low value of $X 6$ the pattern passes only once over the surface (inducing high roughness) whilst with the highest value, 17 times.

- X3 (influential): an augmentation of the radial engagement induces a degradation of the roughness. This phenomenon may be explained by the augmentation of pre-polishing forces.

- X4 (influential): an augmentation of the spindle rotation increases surface roughness. 
- $X 1$ (influential): a high level of the grit number (320) reduces surface roughness. Thereby, a small grit size reduces roughness.

- X2 (not very influential): lubrication improves surface roughness slightly.

- X8 (not very influential): a triangular pattern reduces surface roughness slightly compared to a trochoidal pattern.

- X5 (not influential): the feed rate does not significantly influence surface roughness.

\begin{tabular}{|l|l|l|}
\cline { 2 - 3 } \multicolumn{1}{c|}{} & Roughness: b0 & 2.16 \\
\hline Grit number & Roughness: b1 & -0.48 \\
\hline Lubrication & Roughness: b2 & -0.25 \\
\hline Radial engagement & Roughness: b3 & 0.73 \\
\hline $\boldsymbol{R P M}$ & Roughness: b4 & 0.58 \\
\hline $\boldsymbol{V} f$ & Roughness: b5 & -0.11 \\
\hline $\boldsymbol{a}$ & Roughness: b6 & -1.01 \\
\hline $\boldsymbol{N}$ & Roughness: b7 & -1.16 \\
\hline Pattern & Roughness: b8 & -0.11 \\
\hline
\end{tabular}

Table 5: Numerical model of the surface roughness
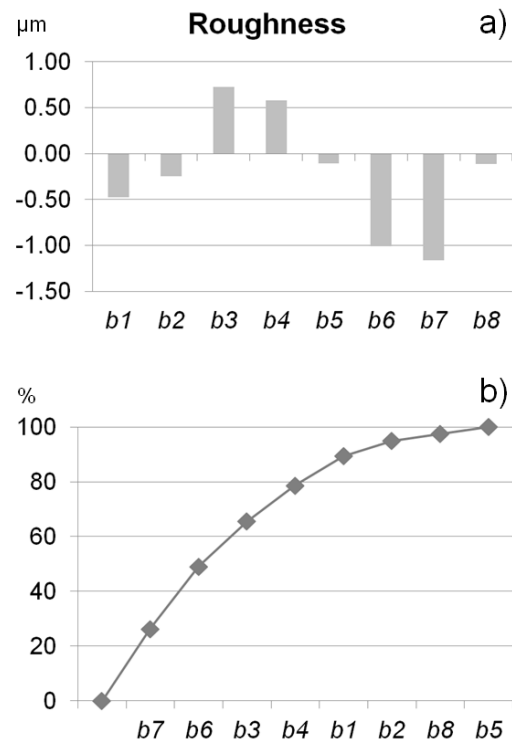

Fig. 9: Model coefficients for surface roughness: a) Histogram and b) Pareto chart

\section{4) Optimization of factors: response surface of DOE}

4.1) Experiment definition

The aim of the proposed work is to optimize the pre-polishing operation factors; this means (§3.2) reducing the pre-polishing cost per volume controlling the surface roughness obtained. The screening design of experiment proposed (section §3) highlights the influential factors on the pre-polishing operation:

- Pre-polishing cost per volume: three main influential factors are, starting with the highest: $X 3, X 1$ and $X 7$.

- Surface Roughness is influenced by (starting with the highest): $X 7, X 6$ and $X 3$.

The study presented proposes a response surface to optimize three main factors: $X 3, X 6$ and $X 7$. These factors will be optimized to reduce pre-polishing cost per volume (objective 
function defined in section §3.2) controlling surface roughness. On the other hand, other factors are fixed for response surface DOE tests:

- Grit number of $150(X 1=-1)$, to reduce production cost with little effect on surface roughness.

- Lubrication off $(X 2=-1)$, this factor does not have a major influence; the lubrication will be suppressed during the response surface tests.

- RPM $(X 4=1)$, this factor does not have great effect on pre-polishing optimization and will be selected equal to $12,000 \mathrm{rpm}$ to carry out the response surface tests.

- $V f(X 5=0)$, this factor does not have a major influence and it is fixed at $2,000 \mathrm{~mm} / \mathrm{min}$ for the response surface tests.

- Pattern shape $(X 8=1)$, using a triangular shape reduces production cost and improves surface roughness.

The response surface proposed uses three levels for each factor $(X 3, X 6$ and $X 7)$. These levels are presented in table 6 . Table 7 presents the experiments carried out and the results obtained. Two response parameters are implemented: pre-polishing cost per volume and surface roughness.

\begin{tabular}{|l|l|l|l|}
\hline & Low level $(-1)$ & Median level $(0)$ & High level $(+1)$ \\
\hline X3: Radial engagement $(\mathrm{mm})$ & 0.05 & 0.1 & 0.15 \\
\hline X7: $\mathrm{N}$ (pattern $/ \mathrm{mm})$ & 0.5 & 2.5 & 4 \\
\hline X6: a $(R=4 \mathrm{~mm})$ & 7 & 4 & 1 \\
\hline
\end{tabular}

Table 6: Factor values tested in the response surface of DOE

\begin{tabular}{|l|l|l|l|l|l|l|l|}
\hline $\begin{array}{l}\text { Experiment } \\
\text { number }\end{array}$ & $X 3$ & $X 7$ & $X 6$ & $\begin{array}{l}Q \\
\left(\mathrm{~mm}^{3} / \mathrm{s}\right)\end{array}$ & $\begin{array}{l}\text { Wear_speed } \\
\left(\mathrm{mm}^{2} / \mathrm{s}\right)\end{array}$ & $\begin{array}{l}P P \_ \text {cost/Vol } \\
\left(\in / \mathrm{mm}^{3}\right)\end{array}$ & $\begin{array}{l}\text { Roughness } \\
(\mu \mathrm{m})\end{array}$ \\
\hline 1 & -1 & -1 & -1 & 0.0281 & 0.0182 & 4.74 & 2.34 \\
\hline 2 & 1 & -1 & -1 & 0.5586 & 0.0402 & 0.45 & 6.74 \\
\hline 3 & -1 & 1 & -1 & 0.0099 & 0.0018 & 4.50 & 1.08 \\
\hline 4 & 1 & 1 & -1 & 0.0987 & 0.0045 & 0.60 & 1.65 \\
\hline 5 & -1 & -1 & 1 & 0.0215 & 0.0171 & 5.91 & 2.16 \\
\hline 6 & 1 & -1 & 1 & 0.3278 & 0.0216 & 0.46 & 1.83 \\
\hline 7 & -1 & 1 & 1 & 0.0120 & 0.0023 & 3.92 & 1.13 \\
\hline 8 & 1 & 1 & 1 & 0.1964 & 0.0100 & 0.45 & 1.61 \\
\hline 9 & -1 & 0 & 0 & 0.0157 & 0.0045 & 3.75 & 1.23 \\
\hline 10 & 1 & 0 & 0 & 0.1917 & 0.0089 & 0.43 & 1.32 \\
\hline 11 & 0 & -1 & 0 & 0.2272 & 0.0337 & 0.96 & 2.45 \\
\hline 12 & 0 & 1 & 0 & 0.1170 & 0.0108 & 0.80 & 1.37 \\
\hline 13 & 0 & 0 & -1 & 0.0800 & 0.0064 & 0.87 & 1.63 \\
\hline 14 & 0 & 0 & 1 & 0.0669 & 0.0070 & 1.09 & 1.83 \\
\hline 15 & 0 & 0 & 0 & 0.0823 & 0.0072 & 0.90 & 1.71 \\
\hline $15 \_1$ & 0 & 0 & 0 & 0.0998 & 0.0068 & 0.72 & 1.31 \\
\hline $15 \_2$ & 0 & 0 & 0 & 0.0789 & 0.0074 & 0.95 & 1.63 \\
\hline $15 \_3$ & 0 & 0 & 0 & 0.0752 & 0.0070 & 0.96 & 1.75 \\
\hline
\end{tabular}

Table 7: Response surface experiments and results

4.2) Result and discussion

To carry out the optimization step, a model was associated with both responses (cost per volume and roughness). This model is a second order DOE equation (Eq. 9).

$Y=b 0+b 3 \cdot X 3+b 7^{\star} X 7+b 6^{\star} X 6+b 33 \cdot X 3^{2}+b 77 \cdot X 7^{2}+b 66 \cdot X 6^{2}+b 37 \cdot X 3 \cdot X 7+b 36 \cdot X 3 \cdot X 6+b 76 \cdot X 7 \cdot X 6$ 


\begin{tabular}{|l|l|l|}
\hline & $\begin{array}{l}\text { PP_cost/Vol } \\
\left(€ / \mathrm{mm}^{3}\right)\end{array}$ & $\begin{array}{l}\text { Roughness } \\
(\mu \mathrm{m})\end{array}$ \\
\hline b0 & 0.73 & 1.42 \\
\hline b3 & -2.04 & 0.52 \\
\hline$b 7$ & -0.23 & -0.87 \\
\hline b6 & 0.07 & -0.49 \\
\hline b33 & 1.41 & -0.07 \\
\hline$b 77$ & 0.19 & 0.57 \\
\hline b66 & 0.29 & 0.39 \\
\hline b37 & 0.30 & -0.38 \\
\hline b36 & -0.09 & -0.60 \\
\hline b76 & -0.24 & 0.64 \\
\hline
\end{tabular}

Table 8: Coefficients of the two response surfaces

Table 8 presents the values of the Eq. 9 coefficients for both responses. Subsequently, table 8 models are presented as a new Figure (Fig. 10 and 11). To represent these models (Eq. 9), a 4D space is necessary: 3D for the factors (X3, $X 7$ and $X 6)$ and $1 D$ for the response values. To do this, we propose to use a 3D space with one axe for each factor. Thereafter, a sphere is placed along a grid of points on this space. For the figures presented (Fig. 10 and 11 ), this grid is obtained using the values $-1,0$ and 1 on each axis inducing 27 points. The diameter and the color of each sphere are functions of the value of the modeled response in each point. This representation means the direction of the variation can be easily appreciated.

4.2.1) Cost per pre-polished volume response surface

The objective is to reduce the pre-polishing cost per volume. Fig. 4 presents the 4D graph of the modeled cost per pre-polished volume. This figure highlights that low values of radial engagement ( $X 3=-1$ which correspond to a radial engagement of $0.05 \mathrm{~mm}$ ) must be excluded to maintain reasonable production cost. Furthermore, this figure illustrates an optimal value of the production cost close to the points $X 3=1, \quad X 7=0$ and $X 6=0$. Mathematically-speaking, an optimal value is computed to decrease production cost:

- $X 3=0.72$; radial engagement of $0.136 \mathrm{~mm}$

$-X 7=0.04 ; \mathrm{N}=2.58$ patterns $/ \mathrm{mm}$

$-X 6=0.01 ; a=3.96$, pattern which passes 5 times over each point on the toolpath.

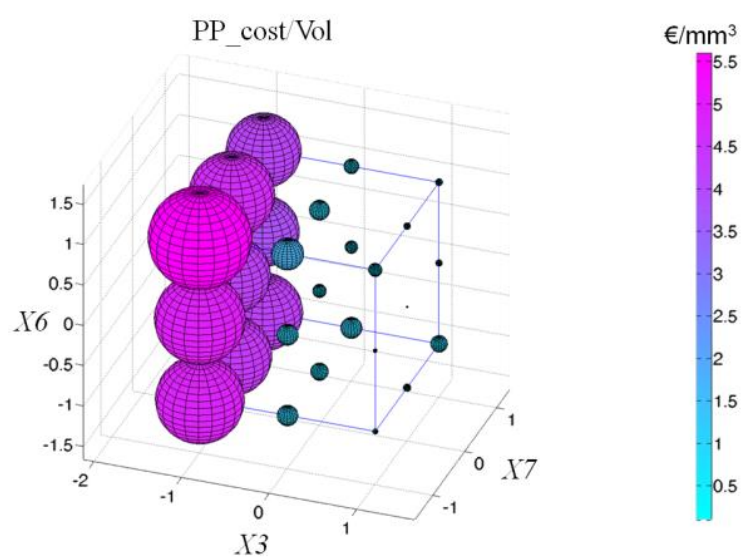

Fig. 10: Response surface of the cost by removed volume

\subsection{2) Surface roughness}

Fig. 11 presents the $4 \mathrm{D}$ representation of the modeled surface roughness. The result obtained confirms the screening design of experiment (\$3.3.3). A low level of $X 7$ (few patterns per millimeter) and $X 6$ (pattern which passes a few times over the same point on the surface) combined with a high level of $X 3$ (high radial engagement) results in the poor 
roughness of the tested area. With this model the optimized point seen in section $\$ 4.2 .1$ provides roughness of $1.7 \mu \mathrm{m}$.

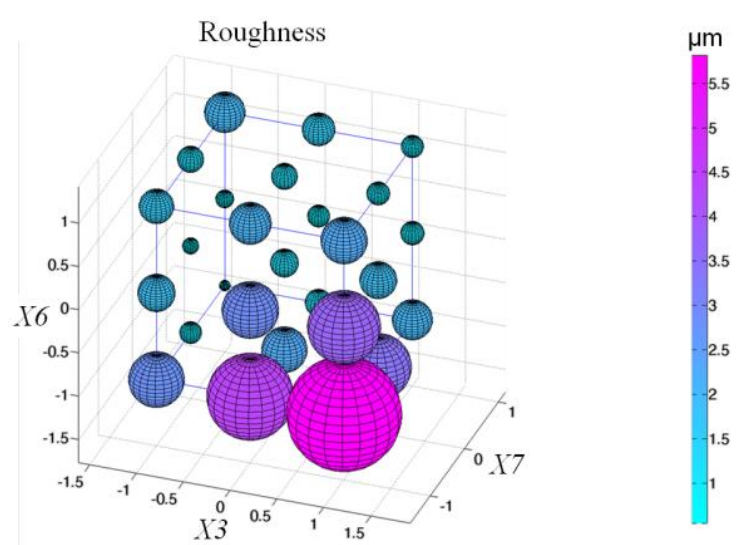

Fig. 11: Response surface of the roughness

4.2.3) Constrained optimization

A contrained optimization is carried out to find the cheapest pre-polishing parameters to ensure a specified roughness. Indeed, using a numerical solver and the obtained model of cost and roughness (presented respectively in sections 4.2.1 and 4.2.2) the optimal values of the $X 3, X 6$ and $X 7$ factors are determined to reduce the pre-polishing cost ensuring the specified roughness. Table 9 presents the optimal pre-polishing parameters to reduce the cost ensuring the specified roughness.

\begin{tabular}{|l|l|l|l|l|}
\hline $\begin{array}{l}\text { Specified } \\
\text { Roughness }(\mu \mathrm{m})\end{array}$ & $X 3$ & $X 7$ & $X 6$ & $\begin{array}{l}\mathrm{PP} \text { cost/Vol } \\
\left(€ / \mathrm{mm}^{3}\right)\end{array}$ \\
\hline 1.8 & 0.7220 & 0.0384 & 0.0125 & 0.33 \\
\hline 1.7 & 0.7218 & 0.0403 & 0.0138 & 0.33 \\
\hline 1.6 & 0.7152 & 0.1011 & 0.0544 & 0.33 \\
\hline 1.5 & 0.7081 & 0.1683 & 0.0996 & 0.33 \\
\hline 1.4 & 0.7003 & 0.2445 & 0.1514 & 0.33 \\
\hline 1.3 & 0.6917 & 0.3346 & 0.2138 & 0.34 \\
\hline 1.2 & 0.6827 & 0.4511 & 0.2982 & 0.35 \\
\hline 1.1 & 0.0730 & 0.7350 & 0.0920 & 0.40 \\
\hline 1 & -0.2698 & 0.7742 & -0.1803 & 1.63 \\
\hline 0.9 & -0.4848 & 0.7989 & -0.3487 & 2.28 \\
\hline 0.8 & -0.6558 & 0.8177 & -0.4811 & 2.90 \\
\hline 0.7 & -0.8020 & 0.8352 & -0.5955 & 3.50 \\
\hline 0.6 & -0.9319 & 0.8495 & -0.6964 & 4.09 \\
\hline 0.55 & -0.9922 & 0.8568 & -0.7435 & 4.38 \\
\hline
\end{tabular}

Table 9: Optimal pre-polishing parameters to reduce the cost ensuring the specified roughness

Results of the table 9 are plotted on figure 12. This figure highlights 2 main areas:

- The value of the roughness specified is between 1.1 and $1.8 \mu \mathrm{m}$. Section $\S 3.3$ demontrates that the radial engagement $(X 3)$ plays the major role in pre-polishing cost. Thus, in this first area, the optimal value of $X 3$ is constant, only the number of patterns per millimeter $(X 7)$ and the pattern shape $(X 6$, which define number of times that the tool passes over a point on the surface) increases. 
- The value of roughness specified is between [0.55; 1]. With a specified roughness of less than $1 \mu \mathrm{m}$ it is impossible to maintain the radial engagement inducing a great increase in pre-polishing cost.
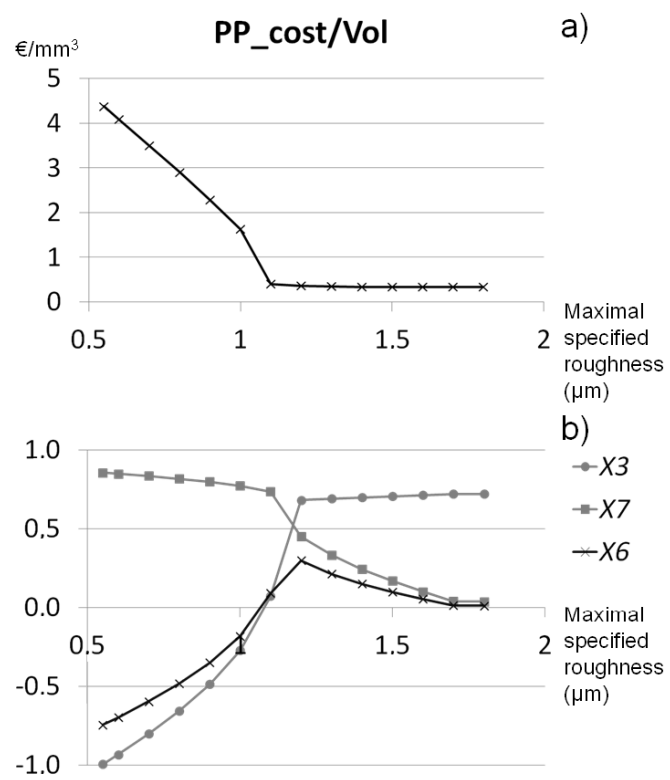

Fig. 12: Optimal pre-polishing parameters to reduce the cost ensuring the specified roughness

\section{Conclusions}

This paper proposes a method to carry out pre-polishing and polishing operations on a common 5-axis milling machine. The method proposed uses a flexible tool comprising sandpaper caps mounted on a rubber support. The pre-polishing operation is carried out with a toolpath composed of a carrier trajectory on which an elementary optimized pattern is repeated. The study presented proposes an experimental optimization of this process. The aim of the optimization is to reduce the pre-polishing process cost by controlling the roughness.

The screening design of experiment implemented highlights that to carry out this aim, big grit sizes with a triangular pattern type need to be used. These experiments also highlight that the lubrication, RPM and feed rate do not play a major role in pre-polishing cost. Furthermore, three main factors must be compromised to optimize the pre-polishing process: radial engagement, number of patterns per millimeter and pattern shape. These factors are optimized using a response surface. This method provides empirical models to estimate the pre-polishing removal material flow rate, the tool wear speed response surface, the cost per pre-polished volume response surface and resulting roughness. Finally, these models are used to define the optimal factors. This optimization highlights two areas based on imposed surface roughness. The first one, which accepts large surface roughness (between 1.1 and $1.8 \mu \mathrm{m})$, authorizes a large radial engagement $(0.136 \mathrm{~mm})$ with reduced pre-polishing cost. On the other hand, in the second area (roughness $<1 \mu \mathrm{m}$ ), the radial engagement must be reduced thus inducing significant production cost increase.

\section{Acknowledgement}

The experimental devices were founded by: European Community, French Ministry of Research and Education, Pays d'Aix Conurbation Community and Aix Marseille Universite. 


\section{References}

[1] Hilerio I, Mathia T, Alepee C (2004) 3D measurements of the knee prosthesis surfaces applied in optimizing of manufacturing process. Wear 257: 1230-1234.

doi: 10.1016/j.wear.2004.05.027

[2] Lison D, Lauwerys R, Demedts M, Nemery B (1996) Experimental research into the pathogenesis of cobalt/hard metal lung disease. Eur Respir J. 9:1024-1028.

doi: $10.1183 / 09031936.96 .09051024$

[3] Tsai MJ, Huang JF (2006) Efficient automatic polishing process with a new compliant abrasive tool. Int. J. of Adv. Manufacturing Technology 30:817-827. doi: 10.1007/s00170005-0126-6

[4] Roswell A, Xi F, Liu G (2006) Modelling and analysis of contact stress for automated polishing. Int. J. of Machine Tools \& Manufacture 46:424-435.

doi: 10.1016/j.jimachtools.2005.05.006

[5] Liao L, Xi F, Liu K (2008) Modeling and control of automated polishing/deburring process using a dual-purpose compliant toolhead. Int. J. of Machine Tools \& Manufacture 48:1454-1463. doi: 10.1016/j.jjmachtools.2008.04.009

[6] Ryuh BS, Park SM, Pennock GR (2006) An automatic tool changer and integrated software for a robotic die polishing station. Mechanism and Machine Theory 41:415-432. doi: 10.1016/j.mechmachtheory.2005.06.004

[7] Nagata F, Hase T, Haga Z, Omoto M, Watanabe K (2007) CAD/CAM-based position/force controller for a mold polishing robot. Mechatronics 17:207-216. doi: 10.1016/j.mechatronics.2007.01.003

[8] Lin FY, Lu TS (2005) Development of a robot system for complex surfaces polishing based on CL data. Int. J. of Adv. Manufacturing Technology 26:1132-1137. doi: 10.1007/s00170-004-2088-5

[9] Wu X, Kita Y, Ikoku K (2007) New polishing technology of free form surface by GC. J. of Materials Processing Technology 187:81-84. doi: 10.1016/j.jmatprotec.2006.11.218

[10] Pessoles X, Tournier C (2009) Automatic polishing process of plastic injection molds on a 5-axis milling center. J. of Materials Processing Technology 209:3665-3673. doi: 10.1016/j.jmatprotec.2008.08.034

[11] Feng D, Sun Y, Du H (2014) Investigations on the automatic precision polishing of curved surfaces using a five-axis machining centre. Int. J. of Adv. Manufacturing Technology 72:1625-1637. doi: 10.1007/s00170-014-5774-y

[12] Chaves-Jacob J, Linares JM, Sprauel JM (2013) Improving tool wear and surface covering in polishing via toolpath optimization. J. of Materials Processing Technology 213:1661-1668. doi: 10.1016/j.jmatprotec.2013.04.005

[13] Wang G, Wang Y, Xu Z (2009) Modeling and analysis of the material removal depth for stone polishing. J. of Materials Processing Technology 209:2453-2463. doi: 10.1016/j.jmatprotec.2008.05.041

[14] Ahn JH, Lee MC, Jeong HD, Kim SR, Cho KK (2002) Intelligently automated polishing for high quality surface formation of sculptured die. J. of Materials Processing Technology 130:339-344. doi: 10.1016/S0924-0136(02)00821-X

[15] Denkena B, De Leon L, Turger A, Behrens L (2010) Prediction of contact conditions and theoretical roughness in manufacturing of complex implants by toric grinding tools. Int. J. of Machine Tools \& Manufacture 50:630-636. doi: 10.1016/j.jjmachtools.2010.03.008

[16] Savio G, Meneghello R, Concheri G (2009) A surface roughness predictive model in deterministic polishing of ground glass moulds. Int. J. of Machine Tools \& Manufacture 49:17. doi: 10.1016/j.ijmachtools.2008.09.001

[17] Xi F, Zhou D (2005) Modeling surface roughness in the stone polishing process. Int. J. of Machine Tools \& Manufacture 45:365-372. doi: 10.1016/j.ijmachtools.2004.09.016

[18] Huissoon JP, Ismail F, Jafari A, Bedi S (2002) Automated Polishing of Die Steel Surfaces. Int. J. of Adv. Manufacturing Technology 19:285-290.

doi: $10.1007 / \mathrm{s} 001700200036$ 